\title{
DETERMINANTS TO GAIN MORE EFFECTIVE MEETINGS IN THE CONTEXT OF VIETNAMESE ORGANIZATIONS
}

\section{LY DAN THANH ${ }^{1,2}$, LE VAN CHON ${ }^{1,2}$, BUI QUANG THONG1,2, NHU-TY NGUYEN1,2,*}

\author{
${ }^{1}$ School of Business, International University (IU), Vietnam \\ ${ }^{2}$ Vietnam National University, HCM City, Vietnam \\ *Corresponding author: nhutynguyen@hcmiu.edu.vn; nhutynguyen@gmail.com
}

\begin{abstract}
Meetings are the primary communicative practice in every organization in order to fulfill the vital consensus, make changes and exchange ideas. Much time and effort are devoted to meetings aiming at information sharing, decision making, and problem solving. Therefore, finding out how voice and leadership power affect meeting effectiveness becomes essential, especially in Vietnamese organizations. First, the paper reviews factors affecting meeting effectiveness including leadership, agenda, substantive conflicts and internal communication. Next, a structured questionnaire was completed by a sample of 157 participants who are working at 31 Vietnamese organizations from a variety of sectors such as tax, banking, health service, airlines, education and business. Finally, the results reveal two antecedents affecting meeting effectiveness: Leadership and Substantive conflict. Leaders play the vital role in formulating an organization vision, making effective plans for vision implementation in reality as well as creating a healthy environment and organizational culture to grow ethical behaviors inside the organization. Their subordinates surely become more committed to the organization when they are working with inspirational leaders who willingly instruct them in uncertainty and encourage their abilities and talents. In addition, it is obvious that during the process of interaction, conflicts may exist and therefore how to resolve conflicts needs to be concerned. At any circumstances, most authors from previous studies believe that when conflicts occur in the meeting, if they are resolved in a constructive way, they will surely bring more benefits for the organizations.
\end{abstract}

Received January 24th 2020; accepted February 18th, 2020; published May 1st, 2020.

2010 Mathematics Subject Classification. 90B50.

Key words and phrases. meeting effectiveness; leadership; substantive conflict; internal communication; agenda.

(C2020 Authors retain the copyrights of their papers, and all open access articles are distributed under the terms of the Creative Commons Attribution License. 


\section{1- INTRODUCTION}

Meetings are the common activities in every organization for several purposes such as fulfilling vital goals, making changes and exchanging ideas [57][65]. Obviously, all meetings are unlike. They vary in several ways, depending on the way people involved, group's size, tools used, management styles, and overall design of the meeting[62][70]. Moreover, much time and effort is devoted to work meetings with the aims of information sharing, decision making, and problem solving [2]. Moreover, meetings offer an exciting gateway to dynamic social processes in organizations [29]. During their meeting interactions, employees exchange information, build common ground, create new ideas, manage relationships, and make or break team climate [54].

Everyday experience makes it evident that, not all meetings are effective [23]. To most working adults, meetings are often viewed as time-wasters but better or worse, it becomes a common workplace activity, occurring everyday around the world. They play the central role of the work environment that can affect many different aspects of one's job, such as job satisfaction with several purposes which may include decision making, information sharing, product design and development. According to the previous reviews and surveys of managers and staff, Nicholas [36] also states that meetings are an important part of one's working life [36]. Above all, meetings need to be held to accomplish several tasks such as reaching important consensus, making changes, coming up with new ideas and the forth. According to previous researches, they reveal that as many as half of these meetings are considered poor in quality [69][66][62][61][68].

Meeting effectiveness, more or less, becomes crucial in Vietnamese organizations under more intense competition. Due to the difference from people in low-context culture in which people tend to be direct, verbal, explicit, and individualistic (US, most of Western Europe, etc.), Vietnamese people belong to high-context culture in which people are considered to be nonverbal, indirect, implicit and collectivistic (Vietnam, Greece, etc.) [25]. In most meetings, subordinates rarely or never raise their ideas, even though they disagree with ideas from their superiors. They are considered to be obedient and passive. In other meetings, some subordinates suggest solutions and receive an approval from their boss but it still doesn't work because the boss did promise but don't keep it. Vietnamese superiors seem to be so conservative and high-power distance [57][59]. They direct the meeting without agenda and lack of internal and problem-focused communication. That's the reason why most meetings in 
Vietnamese organizations have poor quality, leading to diminish staff's job enthusiasm and in turn weakening the organizational commitment. Effective and efficient meetings will motivate subordinates make more contributions and increase commitment to their workplace. Thus, what makes meetings more effective are conducted [61] [58].

The paper aims to build a model of determinants to gain more effective meeting in Vietnamese organizations and through which meeting organizers can direct their meeting's quality more effectively and efficiently, later on facilitate and inspire their subordinates to have more engagement in organizational commitment. The authors design a survey based on the two research questions: What makes subordinates look forward to their work meetings? And What makes subordinate threatened by their work meetings?

\section{2- LITERATURE REVIEW}

\subsection{Meeting effectiveness}

In general, meetings are considered as the strategic role in the Social Practice that brings consequential strategic outcomes to the organization [59][55][52][67]. Furthermore, they can be recognized as the focal points for organizational members' essential activities [17]. There are several types of meeting such as board meetings, committee meetings, departmental meetings and so forth [6].

Rogelberg [40] points out that if the meetings are effective in facilitating organizations and employees to reach their goals, their benefits as an organizational tool is obvious[40]. Thus, meeting effectiveness needs to be improved in order to get higher performance of organizational members. It was closely related to goal attainment and decision satisfaction. The research suggests that effective meetings need to be open in communicating, task-focused, impartial and strict to the use of agenda [3][37].

According to Nixon [37], employees' goals and an organization's goals will lead to meeting effectiveness which is a timed process as well. It should bring benefits to the entire organization. The effective meeting shouldn't be lack of the clear purpose and specific agenda, date, duration and materials [5]. Besides that, Bagire [5] emphasized that the central role of the chairperson who conducts the meeting decides the meeting effectiveness.

Put it another way, some authors state several factors affecting meeting productivity such as irrelevant topics or issues, excessive length of time and poor or inadequate preparation 
[36]. Volkema [47] emphasized that not only the use of agenda and meeting minutes but also the role of group leaders/facilitators controlling the meeting affect the meeting effectiveness [47].

Researchers of ethnography have more explanations in the differentiation of behaviors and attitudes of organizational members, known as organizational culture and they also state that cultural behaviors to some extent enforce the rules, laws and norms. For instances, the meanings of communication are implied by the culture and the context of an organization [42]. Sharing activities among organizational members are shaped by organizational values. The way members share their insights will be supported by behaviors from organizational culture [1]. Undoubtedly, in order to make meeting effective, several factors need to be discussed.

Actually, an organization is mostly influenced by the top leader who has the strongest power in final decision-making. This most powerful person will get involved either directly or indirectly in the meeting decision. A middle manager who hosts the meeting is still there but unable to conclude or give any solutions. As a result, the leader's style and role become a decisive factor in setting organizational culture. It is known as leadership.

\subsection{Leadership}

From the meeting literature perspective, the role of the meeting leader is vital [37]. In a highly diverse workforce, leadership becomes too complicated and needs to be more skillful. It is considered as the key factor in determining whether the organization succeeds [30]. The style of leading should be "simpatico" or "diversity-friendly". A diversity leader from CEO to the first line supervisor is considered as corporate manager who leads subordinates in a fair, effective and respectful way. Nine characteristics that a diversity leader must possess are Sensitive, Impartial, Mediators, Patient, Amiable, Teachers, Involved, Communicators, and Optimistic [15]. Also, in term of leadership, Simola [43] recommends transformational leadership in which leaders aim to transform, motivate and enhance their subordinates' actions and ethical aspirations. It contains four dimensions which are idealized influence, inspirational motivation, intellectual stimulation and individualized consideration [19] [43]. Furthermore, this type of leadership brings more benefits for leading present workgroups because today's followers turn more challenged and empowered. Followers are in the need of an inspirational leader to guide them in uncertainty and intellectually stimulate and encourage their abilities and talents [7]. Put it another way, Kirkpatrick [20] emphasizes leader's traits which include 
achievement, motivation, ambition, energy, tenacity and initiative. Leaders should be provided essential skills such as formulating an organization vision, making effective plans for vision implementation in reality [20].

From most previous studies about leadership, the type of charisma becomes emerging. Partly like ethical one, emotionality is the main dimension in charismatic leadership, the nature of which is not very rational. Problem-solving is not mostly based on authority but rather on personal characteristics [26]. Leadership cannot be fulfilled without groups who have the common goals. Surely, it is hard for leaders or managers effectively achieving organization's goals and that the leader can only achieve goals through followers' efforts and actions [4]. Fry [12] highly appreciates type of servant leadership which consists of four elements such as being a servant first, making sure that other people's needs are served; serving through listening; serving through people building and serving through leadership creation [12]. Similarly, another type of leadership is transformational leadership by which leaders motivates followers by appealing to their higher-order needs and induce employees to transcend self-interest for the sake of the group or the organization [31]. For the emphasis, Wallis [48] strengthens that followers are mainly influenced by leadership's inspiration in which values and beliefs are shared by both leaders and followers. Zhu [51] believes in ethical leaders who behave morally and always tend to create a healthy environment and organizational culture to grow ethical behaviors inside the organization [51]. Above all, researchers in this field point out several definitions of leadership, but to what extent, leadership is defined or limited by its cultural context [48]. In reality, the meeting will be more effective if it is led by the transitional or charismatic leadership. Therefore, the authors propose:

Proposition 1: Leadership significantly affects meeting effectiveness.

Besides leadership, internal communication assists to transform information more specifically and effectively.

\subsection{Internal Communication}

Internal communication is an essential process by which people exchange information, create relationship and build organizational culture and values as well. It is somehow called employee communication [10][30]. Moreover, Martic [27]emphasizes "Through internal communication, executives "pilots" the organization, as well as assure and guide employees to 
follow the mission and goals, encourage loyalty, enhance employees to identify with the organization, increase their motivation and satisfaction with their work, develop mutual positive relationships between employees and the impact on the socialization of employees and organizational culture." [27]. Above all, the best method for facilitating employees to gain specific goals is face-to-face communication [38].

Even though, several blocks in communication happen such as age, gender, previous history of organization, distrust in management, regional differences and so far [44]. If it is symmetrical, it has the positive effect on the relationship between employees and their organization which in turn leads to employee advocacy. Men [30] also claims that there is a linkage among leadership, communication and employee outcomes which positively cultivates the quality of this relationship [31][32]. If communication is effective, it plays as an useful weapon for an organization [41][50].

Communication behaviors have an indirect contribution to the success of the company through employee attitudes[28] . Furthermore, effective communication will foster the closer relationship between senior managers and employees[50]. Especially, in the change process, along with commitment, social and cultural values, it plays a key role in which employees share information, build relationship and make things meaningful [24] [33]. From the same view point, Daly [19] strengthens that internal communication is also a key issue with regard to how successful change management programmers are performed [19]. In the process of constructing a culture of transparency in an organization between management and employees, face-to-face communication is one of the important means of internal communication [34]. Mishra [34] and Vercic [46] strongly state that the executives choose communication strategies in the aim of building trust and engagement with employees and actually, they consider internal communication as a management function in charge of intra-organizational communication [34][46]. And therefore, this is the proposition of the relationship between international communication and meeting effectiveness.

Proposition 2: Internal communication significantly affects meeting effectiveness.

It is unavoidable that internal communication may cause conflicts. How to manage conflicts is considered as art and science. From the perspective of conflict literature, substantive conflict is highly recommended. 


\subsection{Substantive Conflict}

One of the strategic problems occurring in the workplace is conflict. Organizational members, everyday face with resolving conflicts with subordinates, supervisors, peers and stakeholders [39]. Conflict [11][35] normallyrelates to a negative connotation which should be undesirable and avoided. It may originate from an individual, a team or an organization and often results in disagreement and frustration but not all conflicts are harmful. Previous studies reveal that groups in conflict would terminate or reach a consensus in decision-making [13][22] meetings. Esquive [11] also finds out the positive effect of conflict on the process of making decision. Conflict consists of two different types which are called C-type conflict and A-type conflict. While the former is substantive, issue-related differences of opinion that tend to improve team effectiveness and originated from the agenda's content, the latter depends on personal feelings, someone's own agenda or interpersonal struggle related to the group's agenda problems[11][13]. Guetzkow [13] named these two types: subjective conflict and affective conflict.

Conflict is caused by 3 main ingredients which are individual characteristics, interpersonal factors and issues. The three most prominent categories of conflict management style are avoidance, distributive, and integrative [21]. While avoidance style tends to ignore or shift a conversation to a different issue, distributive is a confrontive approach. Among the three styles, integrative brings more effective decision, implying an effort to come to the best or at least agreeable solution for all concerned members. From another perspective, conflict is also classified by the two dimensions of assertiveness and cooperativeness, expressed by five conflict-handling modes including competing, collaborating, compromising, avoiding vand accommodating) [45]. Moderators that can influence in conflict [18] are "amplifiers (those variables that amplify the conflict-outcome relationship, strengthening both the positive and negative effects), suppressors (those variables that weaken both the positive and negative effects on outcomes), ameliorators (those variables that decrease negative effects and increase positive effects), and execrators (those variables that increase negative effects of conflict and decrease positive effects)" [18]. Importantly, effective managers select a range of different strategies in different contexts, aiming at achieving a desirable outcome[14]. Ultimately, substantive conflict is considered to have much positive effects on meeting effectiveness. Therefore, the proposition is suggested as: 
Proposition 3: Substantive conflict significantly affects meeting effectiveness.

Even though, several prominent factors affecting meeting effectiveness are abovementioned, it would be inadequate without agenda of the meeting in advance.

\subsection{Agenda}

Agenda is another meeting issue that need to be concerned because it affects member preparation, time-use effectiveness and finally, meeting effectiveness [37]. Depending on agenda-based meeting management, an agenda enables meeting leaders to manage one or more meetings for locally-located participants, remote participants or both [8].

Basically, an agenda makes teamwork more task-focused and issue-focused. It is viewed as the "purchase point" decision for team members [16]. A formal meeting agenda brings meeting participants or members involved specific information about the structure of a meeting time, place, topics related, or other preparatory work [49]. Moreover, it keeps the meeting happening in the correct sequence and covering the right topics. There are a couple of benefits for either the chair of the meeting to make sure the agenda is correct or participants to prepare for a meeting [6]. Above all, an agenda in advance is indispensable to meeting effectiveness. As a result, the proposition is suggested as:

Proposition 4: Agenda significantly affects meeting effectiveness.

To sum up, from previous studies of the meeting literature, it seems that there are four dominant factors affecting meeting effectiveness in the context of Vietnamese organizations as the authors' suggestion in the following conceptual model.

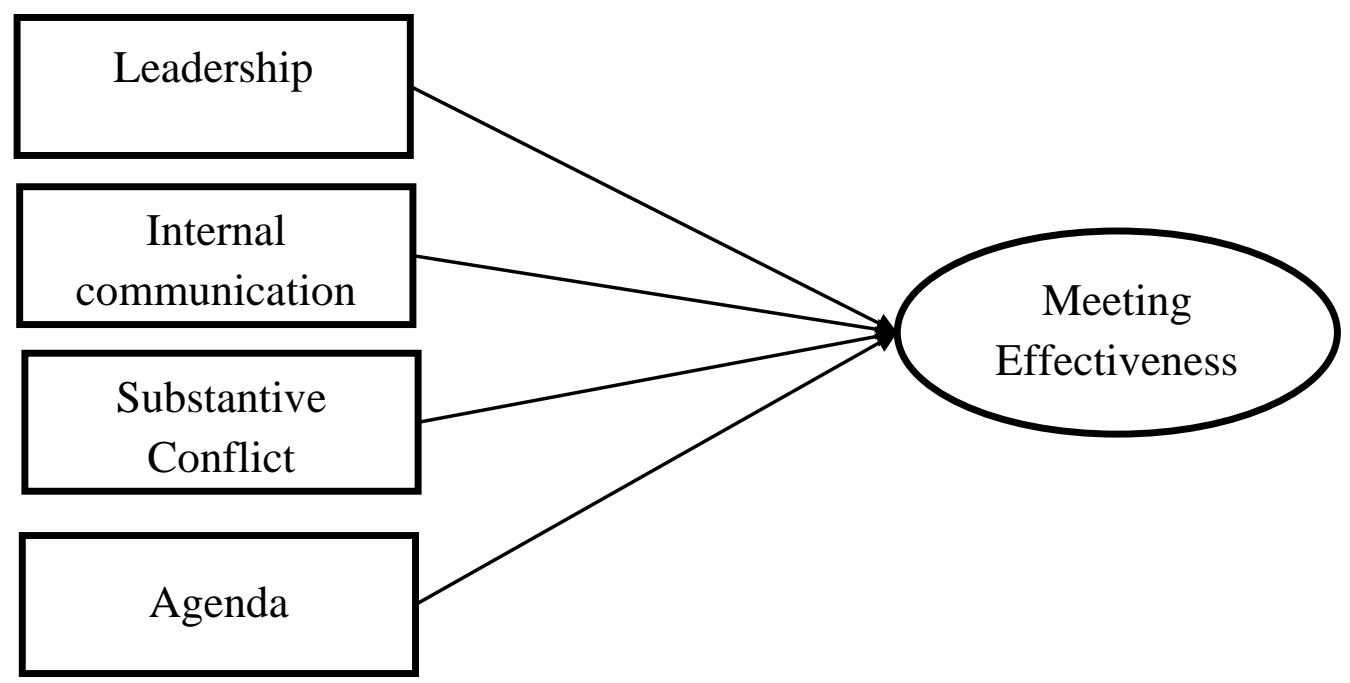

The conceptual model 


\section{3- METHOD AND RESULTS}

\section{Data Collection}

The data for the research is based on the survey of one hundred and fifty-seven participants who are working at about 31 Vietnamese organizations from a variety of sectors such as tax, banking, health service, airlines, education and business. Specifically, they all are subordinates with various titles from middle managers to staffs, but not in the top management board. In other words, participants are those who lead a meeting, but still are led by other meeting organizers. The questionnaires included five variables: meeting effectiveness, agenda, leadership, substantive conflict and internal communication and were distributed as hard copies that required handwritten responses. These questions contained 30 items using fivepoint Likert scale: totally disagree, disagree, neutral, agree, and totally agree. A total of completed 157 questionnaires performed within five months in Hochiminh City and Kien Giang Province in southern Vietnam were returned and valid. Quantitative research is conducted by non-probability sampling.

\section{Data analysis and Results}

To ensure the items in the questionnaire and the model to be valid and reliable, a part of the questionnaires is conducted as a pilot test for testing the clarity of contents and misspelling. Then, one hundred and fifty-seven participants are surveyed. The result is applied SPSS software with the following steps: Statistic analysis; evaluation of Cronbach alpha for each factor; EFA, then used Amos to analyze SEM model based on the EFA's result.

The result of descriptive statistics shows that it ranged with mean from 3.55 to 4.17 (Table 1). 
Table 1. Descriptive statistics

\begin{tabular}{|c|c|c|c|c|c|}
\hline & $\mathrm{N}$ & Minimum & Maximum & Mean & Std. Deviation \\
\hline AGEN1.Meetings start on time. & 157 & 1 & 5 & 4.13 & .899 \\
\hline AGEN2.Meetings end when you expect them to end. & 157 & 1 & 5 & 3.66 & 1.010 \\
\hline AGEN3.A written agenda is provided before the meetings. & 157 & 1 & 5 & 4.09 & .929 \\
\hline AGEN4.Overall, I am satisfied with the meeting process. & 157 & 1 & 5 & 3.81 & .761 \\
\hline AGEN5.The meeting was time well spent. & 157 & 1 & 5 & 3.80 & .845 \\
\hline AGEN6.A verbal agenda is provided at the meetings. & 157 & 1 & 5 & 3.92 & .874 \\
\hline $\begin{array}{l}\text { LDS1.In the meeting, the leader will express the objective } \\
\text { opinion with followers. }\end{array}$ & 157 & 1 & 5 & 3.95 & .830 \\
\hline $\begin{array}{l}\text { LDS2.In the meeting, the leader will remain impartial } \\
\text { rather than speaking out and expressing his/her views. }\end{array}$ & 157 & 1 & 5 & 3.90 & .846 \\
\hline $\begin{array}{l}\text { LDS3.In the meeting, the leader will express the } \\
\text { nonconservative opinion with followers. }\end{array}$ & 157 & 1 & 5 & 3.85 & .856 \\
\hline $\begin{array}{l}\text { LDS4.In the meeting, the leader will interact with } \\
\text { followers- social distance is low. }\end{array}$ & 157 & 1 & 5 & 3.90 & .826 \\
\hline $\begin{array}{l}\text { LDS5.In the meeting, the leader will support and } \\
\text { encourage followers to express their ideas. }\end{array}$ & 157 & 1 & 5 & 4.03 & .812 \\
\hline $\begin{array}{l}\text { LDS6.In the meeting, the leader will foster group goals. } \\
\text { LDS7.In the meeting, the leader will communicate a high }\end{array}$ & 157 & 1 & 5 & 4.17 & .741 \\
\hline $\begin{array}{l}\text { degree of confidence in the followes' ability to meet } \\
\text { expectations. }\end{array}$ & 157 & 1 & 5 & 3.83 & .831 \\
\hline $\begin{array}{l}\text { LDS8.In the meeting, the leader will express high } \\
\text { performance expectations for followers. }\end{array}$ & 157 & 1 & 5 & 4.06 & .727 \\
\hline $\begin{array}{l}\text { LDS9.In the meeting, the leader provides } \\
\text { recognition/rewards when others reach their goals. }\end{array}$ & 157 & 1 & 5 & 3.87 & .830 \\
\hline $\begin{array}{l}\text { LDS10.In the meeting, the leader empowers his/her } \\
\text { followers to make the final decision. }\end{array}$ & 157 & 1 & 5 & 3.55 & .957 \\
\hline $\begin{array}{l}\text { CFT1. When conflicts happen in the meeting, your leader } \\
\text { and the group search for the real causes of the problem } \\
\text { and find out suitable solutions. }\end{array}$ & 157 & 1 & 5 & 3.94 & .778 \\
\hline $\begin{array}{l}\text { CFT2. When conflicts happen in the meeting, your leader } \\
\text { provides the accurate information and solves together } \\
\text { with flollowers. }\end{array}$ & 157 & 1 & 5 & 3.93 & .743 \\
\hline $\begin{array}{l}\text { CFT3. When conflicts happen in the meeting, your leader } \\
\text { combines his/her opinion with the group's opinion for } \\
\text { making the final decision. }\end{array}$ & 157 & 1 & 5 & 3.84 & .820 \\
\hline $\begin{array}{l}\text { IC1.This company encourages differences of opinions. } \\
\text { IC2.Most communication between management and other }\end{array}$ & 157 & 1 & 5 & 3.89 & .725 \\
\hline $\begin{array}{l}\text { employees in this organization can be said to be two-way } \\
\text { communication. }\end{array}$ & 157 & 1 & 5 & 3.80 & .838 \\
\hline $\begin{array}{l}\text { IC3.Your leader makes you feel comfortable working with } \\
\text { him/her. }\end{array}$ & 157 & 1 & 5 & 3.85 & .778 \\
\hline
\end{tabular}


IC4.You would feel comfortable working with your leader.

MET1.When the meeting is finally over, you feel satisfied with the results.

MET2.The meeting states each problem with a clear solution.

MET3.Most of conflicts raising in the meeting are solved satisfactorily.

MET4.After the meeting, you achive your work goals.

MET5.After the meeting, you get your leader's understanding about your difficulties.

MET6.After the meeting, you receive your leader's instruction and sympathy with what you are fulfilling.

MET7.The meeting provides you with an opportunity to acquire useful information.

Valid N (listwise)

\begin{tabular}{l|l|l|l|l|}
157 & 1 & 5 & 3.73 & .859 \\
157 & 1 & 5 & 3.80 & .766 \\
157 & 1 & 5 & 3.83 & .839 \\
157 & 1 & 5 & 3.55 & .865 \\
157 & 1 & 5 & 4.01 & .789 \\
157 & 1 & 5 & 3.72 & .861 \\
157 & 1 & 5 & 3.80 & .822 \\
157 & 1 & & & .755 \\
157 & & 5 & 3.98 & \\
\hline
\end{tabular}

EFA factor analysis is classified into 2 steps. While the first step is for independent variables, the second step is for the dependent variable. The first step, 4 independent variables are included in EFA factor analysis with principal components method and rotation varimax. $\mathrm{KMO}$ and Bartlett's test is significant $(\mathrm{p}<.001)$ and Kaiser-Meyer-Olkin Measure of Sampling Adequacy equal to 0.920 (>0.5) (Table 2) and the evaluation of Cronbach alpha is .953.

Table 2. KMO and Bartlett's Test

\begin{tabular}{|c|c|c|}
\hline \multicolumn{2}{|c|}{ Kaiser-Meyer-Olkin Measure of Sampling Adequacy. } & .920 \\
\hline \multirow[t]{3}{*}{ Bartlett's Test of Sphericity } & Approx. Chi-Square & 2593.761 \\
\hline & df & 253 \\
\hline & Sig. & .000 \\
\hline
\end{tabular}

After Rotation method Varimax with Kaiser Normalization, 22 items of independent variables are grouped into 4 groups. However, factor 4 contains only 1 item which should be eliminated. Therefore, there actually exits 3 groups with 21 items which are named as Leadership for group 1, Agenda for group 2 and Conflicts for group 3. Meeting effective ness contains 7 items and is also named meeting effectiveness.

The evaluation of Cronbach alpha after EFA analysis for 3 factors: Leadership, Agenda and Conflict are simultaneously at .944; .814; and .817 (Table 3). They all are accepted. 
Table 3. EFA result

\begin{tabular}{|c|c|c|c|c|}
\hline \multicolumn{5}{|c|}{ Rotated Component Matrix ${ }^{a}$} \\
\hline & \multicolumn{4}{|c|}{ Component } \\
\hline & 1 & 2 & 3 & 4 \\
\hline AGEN1 & & & .782 & \\
\hline AGEN2 & & & .806 & \\
\hline AGEN3 & & .731 & & \\
\hline AGEN4 & & .661 & & \\
\hline AGEN5 & .543 & .512 & & \\
\hline AGEN6 & & .742 & & \\
\hline LDS1 & .598 & & & \\
\hline LDS2 & .584 & & & \\
\hline LDS3 & .649 & & & \\
\hline LDS4 & .767 & & & \\
\hline LDS5 & .722 & & & \\
\hline LDS6 & .674 & & & \\
\hline LDS7 & .604 & & & \\
\hline LDS8 & .523 & & & \\
\hline LDS9 & & & & \\
\hline LDS10 & & & & .876 \\
\hline CFT1 & .572 & & .538 & \\
\hline CFT2 & .619 & & .546 & \\
\hline CFT3 & .572 & & & \\
\hline IC1 & .587 & & & \\
\hline IC2 & .775 & & & \\
\hline IC3 & .826 & & & \\
\hline IC4 & .775 & & & \\
\hline Eigenvalue & 7.829 & 2.568 & 2.637 & \\
\hline Cumulative & 60.222 & 64.294 & 65.917 & \\
\hline Cronbach Alpha & .944 & .814 & .817 & \\
\hline
\end{tabular}

Next, the depedent variable "Meeting effectiveness" is evaluated by KMO and Barlett's Test and EFA analysis. The result is that the evaluation of Cronbach alpha for dependent variable "Meeting effectiveness" is .909 which is also accepted. Furthermore, KMO and Bartlett's test is significant $(\mathrm{p}<.001)$ and Kaiser-Meyer-Olkin Measure of Sampling Adequacy equals to $0.891(>0.5)$ and factor loadings are all more than .50 .

Table 4. KMO and Bartlett's Test

KMO and Bartlett's Test

\begin{tabular}{|c|c|c|}
\hline \multicolumn{2}{|c|}{ Kaiser-Meyer-Olkin Measure of Sampling Adequacy. } & .891 \\
\hline \multirow[t]{3}{*}{ Bartlett's Test of Sphericity } & Approx. Chi-Square & 644.649 \\
\hline & Df & 21 \\
\hline & Sig. & .000 \\
\hline
\end{tabular}


Table 5. Component Analysis

Communalities

\begin{tabular}{|l|r|r|}
\hline & \multicolumn{1}{|c|}{ Initial } & Extraction \\
\hline MET1 & 1.000 & .683 \\
MET2 & 1.000 & .715 \\
MET3 & 1.000 & .645 \\
MET4 & 1.000 & .693 \\
MET5 & 1.000 & .598 \\
MET6 & 1.000 & .628 \\
MET7 & 1.000 & .579 \\
\hline
\end{tabular}

CFA Factor Analysis

Figure 1. Results of CFA concepts of research model (standardized)

$\mathrm{P}=.000$;

$\mathrm{CFI}=.871 ; \mathrm{TLI}=.858 ; \mathrm{GFI}=.743 ;$

RMSEA $=.089$.

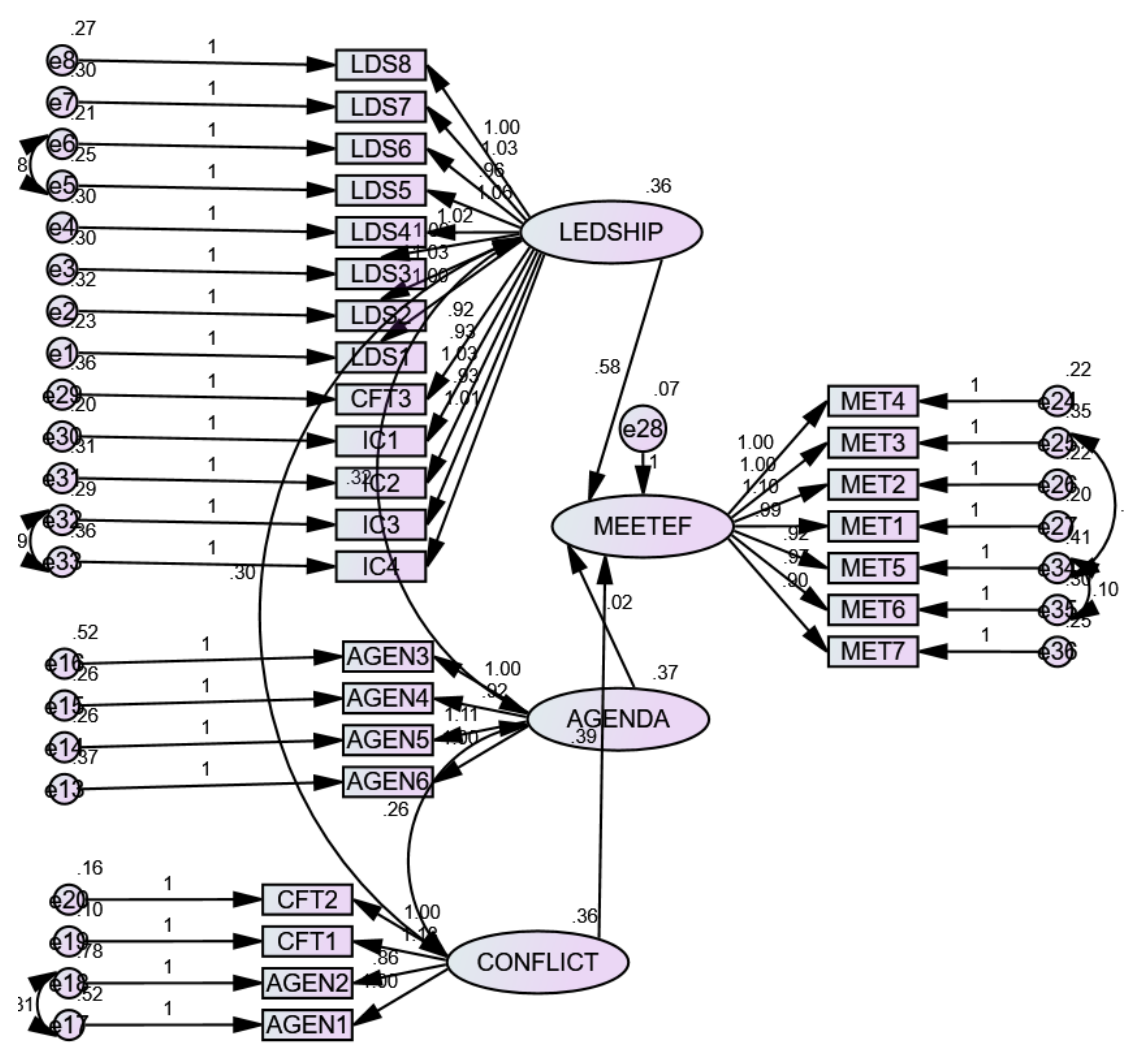


Table 6. Standardized Regression Weights

\begin{tabular}{|c|c|c|c|c|c|c|c|}
\hline & & & Estimate & S.E. & C.R. & $\mathrm{P}$ & Label \\
\hline MEETEF & $<---$ & LEDSHIP & .683 & .255 & 2.679 & .007 & \\
\hline MEETEF & $<--$ & AGENDA & -.023 & .185 & -.124 & .901 & \\
\hline MEETEF & $<--$ & CONFLICT & .408 & .122 & 3.353 & $* * *$ & \\
\hline LDS2 & $<--$ & LEDSHIP & 1.216 & .136 & 8.912 & $* * *$ & \\
\hline LDS3 & $<--$ & LEDSHIP & 1.261 & .138 & 9.128 & $* *$ & \\
\hline LDS4 & $<--$ & LEDSHIP & 1.215 & .133 & 9.115 & $* * *$ & \\
\hline LDS5 & $<--$ & LEDSHIP & 1.250 & .131 & 9.525 & $* *$ & \\
\hline LDS6 & $<--$ & LEDSHIP & 1.135 & .120 & 9.476 & $* * *$ & \\
\hline LDS7 & $<--$ & LEDSHIP & 1.214 & .134 & 9.055 & $* * *$ & \\
\hline LDS8 & $<--$ & LEDSHIP & 1.000 & & & & \\
\hline AGEN5 & $<---$ & AGENDA & 1.260 & .176 & 7.172 & $* * *$ & \\
\hline AGEN4 & $<--$ & AGENDA & 1.012 & .150 & 6.736 & $* * *$ & \\
\hline AGEN3 & $<--$ & AGENDA & 1.000 & & & & \\
\hline AGEN1 & $<--$ & CONFLICT & 1.000 & & & & \\
\hline AGEN2 & $<--$ & CONFLICT & .864 & .108 & 8.003 & $* * *$ & \\
\hline CFT1 & $<--$ & CONFLICT & 1.175 & .077 & 15.185 & $* * *$ & \\
\hline CFT2 & $<---$ & CONFLICT & 1.000 & & & & \\
\hline MET04 & $<---$ & MEETEF & 1.000 & & & & \\
\hline MET03 & $<---$ & MEETEF & 1.001 & .101 & 9.885 & $* * *$ & \\
\hline MET02 & $<---$ & MEETEF & 1.101 & .094 & 11.677 & $* * *$ & \\
\hline MET01 & $<---$ & MEETEF & .984 & .087 & 11.347 & $* * *$ & \\
\hline CFT3 & $<--$ & LEDSHIP & 1.090 & .132 & 8.244 & $* * *$ & \\
\hline IC01 & $<---$ & LEDSHIP & 1.091 & .117 & 9.329 & $* * *$ & \\
\hline IC02 & $<---$ & LEDSHIP & 1.230 & .135 & 9.099 & $* * *$ & \\
\hline IC03 & $<---$ & LEDSHIP & 1.110 & .125 & 8.851 & $* * *$ & \\
\hline IC04 & $<---$ & LEDSHIP & 1.218 & .139 & 8.787 & $* * *$ & \\
\hline MET05 & $<---$ & MEETEF & .914 & .104 & 8.827 & $* * *$ & \\
\hline MET06 & $<--$ & MEETEF & .970 & .096 & 10.140 & $* * *$ & \\
\hline MET07 & $<---$ & MEETEF & .898 & .088 & 10.239 & $* * *$ & \\
\hline
\end{tabular}


The results of CFA factor analysis of the research model are presented in Figure 1. While processing data, the authors eliminate two items which are LDS1 and AGEN6 because they are insignificant in the model in order to produce the valid results. These results show that the conditions are stated as follow: $\mathrm{P}<0.05 ; \mathrm{CFI}, \mathrm{GFI} \geq 0.8$ and RMSEA is approximately0.08. They all meet the requirements. Considering the above conditions, the model is consistent with market data.

Based on the results in Table 6, the parameters (standardized) are statically significant $(\mathrm{p}<0.05)$. According to the regression weight between factors shown, two factors that are Leadership and Substantive conflict have significant effects on Meeting effectiveness with weight of 0.683 and 0.408 and P-value <0.05respectively, while Agenda with weight of -0.023 and P-value 0.901 does not. In other words, Leadership affects positively meeting effectiveness and when Leadership goes up by 1 standard deviation, Meeting effectiveness goes up by 0.683 standard deviation. Similarly, when Substantive conflict increases by 1 standard deviation, Meeting effectiveness increases by 0.408 standard deviation.

\section{4- DISCUSSION}

Meetings become frequent activities in every organization for such purposes as fulfilling vital goals, making changes and exchanging ideas. It is evident that meeting effectiveness is closely related to goal attainment and decision satisfaction. Therefore, meetings need be improved in an effective and efficient way so that subordinates make more contributions and increase commitment to their workplace.

It is found that meeting effectiveness is significantly influenced by the two dominant factors consisting of leadership and substantive conflict. From previous study, Kirkpatrich [20] confirms that leader's styles such as achievement, motivation, ambition, energy, tenacity and initiative are highly appreciated. They should be trained essential skills: formulating an organization vision, making effective plans for vision implementation in reality [20]. Besides, both leaders and subordinates should have the common goals [4]. Servant leadership in which leaders need to make sure that other people's needs are served by listening and observing is strongly recommended by [12]. Furthermore, Wallis [48]and Zhu [51] also emphasize that leadership's inspiration should be shared with followers and the leaders should behave morally 
and always expect to create a healthy environment and organizational culture to grow ethical behaviors inside the organization.

Actually, whether the meeting is effective or not depends on the meeting leaders' guide. Actually, leadership plays a very important role in transforming, motivating and enhancing subordinates 'actions and ethical aspirations. Subordinates surely become more committed to the organization when they are working with inspirational leaders who willingly instruct them in uncertainty and encourage their abilities and talents [7]. That's why leadership strongly affects meeting effectiveness in reality.

During the process of interaction, conflicts may exist and therefore, how to resolve conflicts needs to be concerned. Conflicts are double-faced. While affective conflict may improve and bring benefits to team effectiveness, subjective one may destroy the relationship and reduce members' job performance [11][13]. Transparently, from previous studies, substantive conflicts which are issue-related differences of opinion are proved to aim at improving team effectiveness. It also confirms that substantive conflicts positively influence meeting effectiveness.

In short, empirically, in order to host a meeting effectively, meeting organizers should control their leadership in a proper way and solve thoroughly any conflicts raising in a constructive way.

\section{5-IMPLICATIONS AND CONCLUSION}

\section{Implications}

For future research, based on the literature of meeting effectiveness, it also has the great impact on organizational commitment. Therefore, what we should do next is to find out the relationship between meeting effectiveness and organizational commitment which motivates and inspires subordinates to engage more closely in their organization. 


\section{Conclusion}

The findings show practical meaning of meeting effectiveness in the context of Vietnamese organizations. Empirically, the two significant factors that mainly affect meeting effectiveness are Leadership and Substantive conflict. Based on the previous studies in the world [16] agenda plays an essential role in the meeting, but the result shows that it's statistically insignificant with P-value equals to $0.90>0.05$ which is showed in Table 6 - Standardized Regression Weights. Regarding to national values differences across the worldwide subsidiaries, while according to Western cultures, people belong to polychromic culture, they tend to be on time, and Vietnamese people almost belonging to Asian culture tend to be influenced by polychromic culture [25].

Conflicts of Interest: The author(s) declare that there are no conflicts of interest regarding the publication of this paper.

\section{References}

[1] Alavi, M., Kayworth, T. R., \& Leidner, D. E. An Empirical Examination of the Influence of Organizational Culture on Knowledge Management Practices. J. Manage. Inform. Syst. 22(3)(2005-6), 191-224.

[2] Allen, J., Sands, S., Mueller, S., Frear, K., Mudd, M. and Rogelberg, S. Employees' feelings about more meetings: An overt analysis and recommendations for improving meetings, Manage. Res. Rev. 35(5) (2012), 405-418.

[3] Allen, J. A., Willenbrock, N. L., \& Landowski, N. Linking pre-meeting communication to meeting effectiveness. J. Manager. Psychol. 29(2014), 1064-1081.

[4] Andersen, J. A. Leadership, personality and effectiveness, J. Soc. Econ. 35(6) (2006), 1078-1091.

[5] Bagire, V., Byarugaba, J., \& Kyogabiirwe, J. Organizational meetings: management and benefits, J. Manage. Develop. 34(8)(2015), 960 - 972.

[6] Baker, H. Writing Meeting Minutes and Agenda. Lancashire, UK: Universe of Learning Ltd.(2010).

[7] Bass, B. M., \& Riggio, R. E. Transformational Leadership. London: Lawrence Erlbaum Associates, Inc.(2006).

[8] Butt, D. Agenda based meeting management system, interface and method. Google Patents. (2006).

[9] Daly, P. J. K. F. Internal communication during change management. Corp. Commun. 17(2002), 46-53. 
[10] Deetz, S. Conceptual foundations In The new handbook of organizational communication: Advances in theory, research and methods (pp. 3-46): Thousand Oaks, CA: Sage.(2001).

[11] Esquivel, M. A., \& Kleiner, B. H. The importance of conflict in work team effectiveness, Team Perform. Manage. 2(3)(1996), 42 - 48.

[12]Fry, L. W., Matherly, L. L., Whittington, J. L., \& Winston, B. E. Spiritual Leadership as an Integrating Paradigm for Servant Leadership.Integrat. Spirit. Organiz. Leadership. (2007), 70-82.

[13] Guetzkow, H., \& Gyr, J. An analysis of conflict in decision-making groups. Human Relations, 7(3) (1954), 367-382.

[14]Holmes, J. M.,Marra, M. Leadership and Managing Conflict in Meetings. Int. Pragmat. Assoc. 14(4)(2004), 439-462.

[15]Hopkins, W. E., \& Hopkins, S. A. Diversity Leadership: A mandate for the 21st Century Workforce. J. Leadership Stud. 5(3)(1998), 129-140.

[16] Inglis, S., \& Weaver, L. Designing Agendas to Reflect Board Roles and Responsibilities: Results of a Study, Nonprofit Manage. Leadership, 11(1)(2000), 65-77.

[17]Jarzabkowski, P., \& Seidl, D. The Role of Meetings in the Social Practice of Strategy. Organ. Stud. 29(11)(2008), 1391-1426.

[18]Jehn, K. A., \& Bendersky, C. Intragroup conflict in organizations: a contingency perspective on the conflict-outcome relationship. Res. Organ. Behavior, 25(2003), 187-242.

[19]Judge, T. A., \& Bono, J. E. Five-Factor Model of Personality and Transformational Leadership. J. Appl. Psychol. 85(5)(2000), 751-765.

[20] Kirkpatrick, S. A., \& Locke, E. A. Leadership: Do traits matters? Acad. Manage. Execut. 5(2)(1991), 4860.

[21]Kuhn, T., \& Poole, M. L. Do Conflict Management Styles Affect Group Decision Making?. Human Commun. Res. 26(4)(2000), 558-590

[22] Laursen, B., \& Collins, W. A. Interpersonal Conflict During Adolescence. Psychol. Bull. 115(2)(1994), 197-209.

[23] Leach, D. J., Rogelberg, S. G., Warr, P. B., \& Burnfield, S. G. Perceived meeting effectivenss: The role of Design characteristics. J. Bus. Psychol. 24(2009), 65-76.

[24] Linke, A., \& Zerfass, A. Internal communication and innovation culture: developing a change framework, J. Commun. Manage. 15(4)(2011), 332-348.

[25] Locker, K., \& Keinzler, D. Business and Administrative Communication (9th ed.), Mc Graw, (2009). 
[26] Marjosola, I. A., \& Takala, T. Charismatic leadership, manipulation and the complexity of organizational life. J. Workplace Learning,12 (4) (2000),146-158.

[27] Martic, M. Communication between employees. Paper presented at the Symorg 2014, Serbira, 2014.

[28] Mazzei, A. Promoting active communication behaviours through internal communication,Corp. Commun., Int. J. 15(3)(2010), 221-234

[29] Meinecke, A. L., \& Lehmann-Willenbrock, N. K. Social dynamics at work: Meetings as a gateway, In J. A. Allen, N. Lehmann-Willenbrock, \& S. G. Rogelberg (Eds.), Cambridge handbooks in psychology. The Cambridge handbook of meeting science (p. 325-356). Cambridge University Press, (2015).

[30]Men, L. R. Strategic Internal Communication: Transformational Leadership, Communication Channels, and Employee Satisfaction. Manage. Commun. Q. 28(2)(2014), 264 -284

[31]Men, L. R.Why Leadership Matters to Internal Communication: Linking Transformational Leadership, Symmetrical Communication, and Employee Outcomes. J. Public Relat. Res. 26(2014), 256-279.

[32] Men, L. R., \& Jiang, H. Cultivating Quality Employee-Organization Relationship. Int.J.Strat.Commun. 10(5)(2016), 462-479.

[33]Men, L. R., \& Stacks, D. The Effects of Authentic Leadership on Strategic Internal Communication and Employee-Organization Relationships, J. Public Relat. Res. 26(2014), 301-324.

[34] Mishra, K., Lois Boynton, L., \& Mishra, A. Driving Employee Engagement: The Expanded Role of Internal Communications. Int. J. Bus. Commun. 51(2)(2014), 183 -202.

[35] Morton Deutsch, M., Coleman, P. T., \& Marcus, E. C. Culture and Conflict. In The Handbook of Conflict Resolution (pp. 641). San Francisco, CA 94103-1741 Jossey-Bass A Wiley Imprint, (2006).

[36] Nicholas, C. R., \& Jay, F. N. Meeting Analysis: Findings from Research and Practice, Proceedings of the 34th Annual Hawaii International Conference on System Sciences, Maui, HI, USA.(2001).

[37] Nixon, C. T., \& Littlepage, G. L. Impact of meeting procedures on meeting effectiveness. J. Bus. Psychol. 6(2014), 361-369.

[38] Okanovic, M., Stefanovic, T., \& Suznjevic, M. New Media in Internal Communication. Paper presented at the Symorg 2014, Serbira, (2014).

[39]Putnam, L. L. Communication and Interpersonal Conflict in Organizations, Manage. Commun. Q. 1(1988), 293-301.

[40] Rogelberg, S. G., Leach, D. J., Warr, P. B., \& Burnfield, J. L. “Not Another Meeting!" Are Meeting Time Demands Related to Employee Well-Being? J. Appl. Psychol. 91(1)(2006), 86-96. 
[41]Ruck, K., \& Welch, M.Valuing internal communication; management and employee perspectives. Public Relat. Rev. 38(2012), 223-230.

[42] Safriadi, Hamdat, S., Lampe, M., \& Munizu, M. (2006). Organizational Culture In Perspective Anthropology, Int. J. Sci. Res. Publ. 6(6) (2016), 773-776.

[43] Simola, S., Barling, J., \& Turner, N. (2012). Transformational leadership and Leader's Mode of Care Reasoning,J. Bus. Ethics, 108(2012), 229-237.

[44] Smith, L., \& Mounter, P. Effective Internal Communication. USA: Replika Press Pvt Ltd, (2008).

[45] Thomas, K. W.Conflict and Conflict Management: Reflections and Update. J. Organ. Behavior, 13(1992), 265-274.

[46] Vercic, A. T., Vercic, D., \& Sriramesh, K. Internal Communication: Definition, parameters, and the future. Public Relat. Rev. 38(2012), 223-230.

[47] Volkema, R. J., \& Fred Niederman, F. Planning and Managing Organizational Meetings: An Empirical Analysis of Written and Oral Communications, J.Bus. Commun. 33(1996), 275-296.

[48] Wallis, J. Drawing on revisionist economics to explain the inspirational dimension of leadership. J. Soc. Econ. 31(2002), 59-74.

[49] Welch, D. D. Conflicting Agendas. Eugene, Oregon: Published by The Pilgrim Press, (2008).

[50]Welch, M. (2011). Appropriateness and acceptability: Employee perspectives of internal communication. Public Relat. Rev.38(2) (2012), 246-254.

[51]Zhu, W., May, D. R., \& Avolio, B. J. The Impact of Ethical Leadership Behavior on Employee Outcomes: The Roles of Psychological Empowerment and Authenticity. J. LeadershipOrgan. Stud. 11 (1)(2004), 16-26.

[52] Pham, L. H. T., Nguyen, N. T., \& Tran, T. T. On the factors affecting start-up intention of Millennials in Vietnam. In. J. Adv. Appl. Sci. 6(1)(2019), 1-8.

[53] Nguyen N.T., Nguyen B.P.U., and Tran T.T. Application of grey system theory and ARIMA model to forecast factors of tourism: A case of Binh Thuan Province in Vietnam. Int. J. Adv. Appl. Sci. 7(1)(2020), 87-99.

[54] Nguyen N.T., Nguyen T.T.T., and Tran T.T. Forecasting Vietnamese tourists' accommodation demand using grey forecasting and ARIMA models. Int. J. Adv. Appl. Sci. 6(11)(2019), 42-54.

[55] Nguyen, N. T. Optimizing Factors for Accuracy of Forecasting Models in Food Processing Industry: A Context of Cacao Manufacturers in Vietnam. Ind. Eng. Manage. Syst. 18(4)(2019), 808-824.

[56] Nguyen, N. T., \& Nguyen, L. X. T. Applying DEA Model to Measure the Efficiency of Hospitality Sector: The Case of Vietnam. Int. J. Anal. Appl. 17(6) (2019), 994-1018. 
[57] Nguyen, N. T., \& Tran, T. T. Mathematical development and evaluation of forecasting models for accuracy of inflation in developing countries: a case of Vietnam. Discrete Dyn. Nat. Soc. 2015(2015), Article ID 858157.

[58] Nguyen, N. T., \& Tran, T. T. Facilitating an advanced product layout to prioritize hot lots in $450 \mathrm{~mm}$ wafer foundry in the semiconductor industry. Int. J. Adv. Appl. Sci. 3(6) (2016), 14-23.

[59] Nguyen, N. T., \& Tran, T. T. A two-stage study of grey system theory and DEA in strategic alliance: An application in Vietnamese fertilizing industry. Int. J. Adv. Appl. Sci. 5(9) (2018), 73-81.

[60] Nguyen, N. T., \& Tran, T. T. A Study of the Strategic Alliance for Vietnam Domestic Pharmaceutical Industry: A Dynamic Integration of A Hybrid DEA and GM (1, 1) Approach. J. Grey Syst. 30(4)(2018), 134-151.

[61] Nguyen, N. T., \& Tran, T. T. A two-stage study of grey system theory and DEA in strategic alliance: An application in Vietnamese fertilizing industry. Int. J. Adv. Appl. Sci. 5(9)(2018), 73-81.

[62] Nguyen, N. T., \& Tran, T. T. Raising opportunities in strategic alliance by evaluating efficiency of logistics companies in Vietnam: a case of Cat Lai Port. Neural Comput. Appl. 31(11)(2019), 7963-7974.

[63] Nguyen, N. T., Tran, T. T., Wang, C. N., \& Nguyen, N. T. Optimization of strategic alliances by integrating DEA and grey model. Journal of Grey System, 27(1)(2015), 38-56.

[64] Nguyen, N.T. Performance Evaluation in Strategic Alliances: A Case of Vietnamese Construction Industry. Glob. J. Flex. Syst. Manage. 21 (2020), 85-99.

[65] Tran, T. T. Evaluating and forecasting performance using past data of an industry: An analysis of electronic manufacturing services industry. Int. J. Adv. Appl. Sci, 3(12)(2016), 5-20.

[66] Tran, T. T. An empirical research on selecting the targeted suppliers and purchasing process of supermarket. Int. J. Adv. Appl. Sci. 4(4)(2017), 96-109.

[67] Tran, T. T. Forecasting strategies and analyzing the numbers of incoming students: Case in Taiwanese vocational schools. Int. J. Adv. Appl. Sci. 4(9)(2017), 86-95.

[68] Tran, T. T. Factors affecting the purchase and repurchase intention smart-phones of Vietnamese staff. Int. J. Adv. Appl. Sci. 5(3)(2018), 107-119.

[69] Wang, C. N., Le, T. M., Nguyen, H. K., \& Ngoc-Nguyen, H. Using the Optimization Algorithm to Evaluate the Energetic Industry: A Case Study in Thailand. Processes, 7(2) (2019), 87.

[70] Wang, C. N., Nguyen, N. T., \& Tran, T. T. Integrated DEA models and grey system theory to evaluate past-to-future performance: a case of Indian electricity industry. Sci. World J. 2015 (2015), Article ID 638710. 